\title{
Directing both the Morphology and Packing of Chiral Metal-Organic Frameworks by Cation Exchange Mediated by Nanochannels
}

\author{
Hadar Nasi, Maria Chiara di Gregorio, Qiang Wen, Linda J. W. Shimon, Ifat Kaplan-Ashiri, \\ Tatyana Bendikov, Michal Lahav,* and Milko E. van der Boom*
}

\begin{abstract}
Crystals are among the most challenging materials to design, both at the molecular and macroscopic levels. We show here that metal-organic frameworks, based on tetrahedral pyridyl ligands, can be used as a morphological and structural mold to form a series of other isostructural crystals having different metal ions. The cation exchange is versatile, based on the use of diverse first-row metals; it occurs with retention of the morphology. Different morphologies were obtained by a direct reaction between the ligand and metal salts. An iterative crystal-to-crystal conversion has also been demonstrated by two consecutive cation exchange processes. The primary manganese-based crystals have a complex connectivity characterized by a rare space group (P622). The molecular structure generates two types of homochiral channels that span longitudinally the entire hexagonal prism. These channels mediate the cation exchange, as indicated by energydispersive X-ray spectroscopy combined with scanning electron microscopy measurements on microtome-sectioned crystals. The occurrence of the observed cation exchange is in excellent agreement with the Irving-Williams series $(\mathrm{Mn}<\mathrm{Fe}<$ $\mathrm{Co}<\mathrm{Ni}<\mathrm{Cu}>\mathrm{Zn}$ ) that are associated with the relative stability of the resulting coordination nodes. The overall approach allows for the predictability of the structural properties of rare metal-organic frameworks based on tetrahedral pyridyl ligands at different hierarchies: from elemental composition, molecular packing, and morphology to the bulk properties.
\end{abstract}

\section{INTRODUCTION}

The expression "single-crystal to single-crystal conversion" refers to a wide range of approaches to modify the atomic nature and/or the structure of materials while preserving the long-range crystallinity. ${ }^{1-4}$ Such post-synthetic approaches can provide new properties (e.g., optical, magnetic, structural, and mechanical) otherwise not achievable..$^{5-7}$ Some examples include metal cation exchange in semiconductor particles, ${ }^{8,9}$ quantum dots ${ }^{10,11}$ and perovskites, ${ }^{12,13}$ and galvanic replacement ${ }^{14-16}$ in inorganic materials. Metal-organic frameworks (MOFs) and cages are intriguing materials for single-crystal to single-crystal conversion. Their porous nature favors processes of inclusion and exchange of guests (e.g., solvent, molecular guest, and metal ions) in the inner cavities by physical trapping, coordinative interactions with the metal nodes, or pending moieties. ${ }^{17-23}$ Moreover, dynamic variations of MOF structures were demonstrated upon exposure to external stim$\mathrm{uli}^{24-26}$ and by replacing the constitutive building blocks. ${ }^{2-}$ ${ }^{31}$ The latter process involves a fine balance between flexibility and stability of the overall framework. Metal cation metathesis has been mainly demonstrated using a combination of transition metals and linkers having carboxylic acid coordination sites. ${ }^{28,32-35}$ Such linkers are classified as hard ligands; ${ }^{36}$ they often exhibit planar structures and two or three carboxylic acid groups. For example, Dincă et al. used an exchange of $\mathrm{Zn}^{2+}$ with $\mathrm{V}^{2+}$ and $\mathrm{Ti}^{3+}$ in MOF-5 to generate crystals that were not obtainable by direct synthesis. ${ }^{37} \mathrm{~A}$ reversible exchange of $\mathrm{Cd}^{2+}$ with $\mathrm{Pb}^{2+}$ was reported by Kim and co-workers. ${ }^{38}$ Such exchange processes are less common with MOFs based on metal-pyridine coordination. ${ }^{21,39-42}$ This type of MOFs is known to undergo linker exchange due to its moderate ligand field strength. ${ }^{43,44}$ Nevertheless, it is not obvious that these materials can sustain quantitative metal cation exchanges with the integrity of their frameworks. Competition between selective metal cation exchange and disintegration of the crystal structure is more likely to occur because of the labile nature of such ligands.

We have recently introduced a series of MOFs based on tetrahedral pyridyl ligands with divalent cations, including copper and nickel. ${ }^{45-48}$ These MOFs have an isomorphous crystallographic packing as well as a high level of uniformity (dimensions and morphology). Their fascinating morphologies can be widely varied by using different experimental parameters (e.g., metal-to-ligand ratios, cations, and anions). No additives have been used to direct their morphology and dimensions. To control and predict the packing-morphology relationship, we investigated cation metathesis using a new, manganese-based MOF having the same rare P622 space-group as our other reported crystals (Scheme 1). ${ }^{45-48}$ The crystal structure is porous and exhibits two geometrically and compositionally different channels. Cation metathesis was used here to control and 


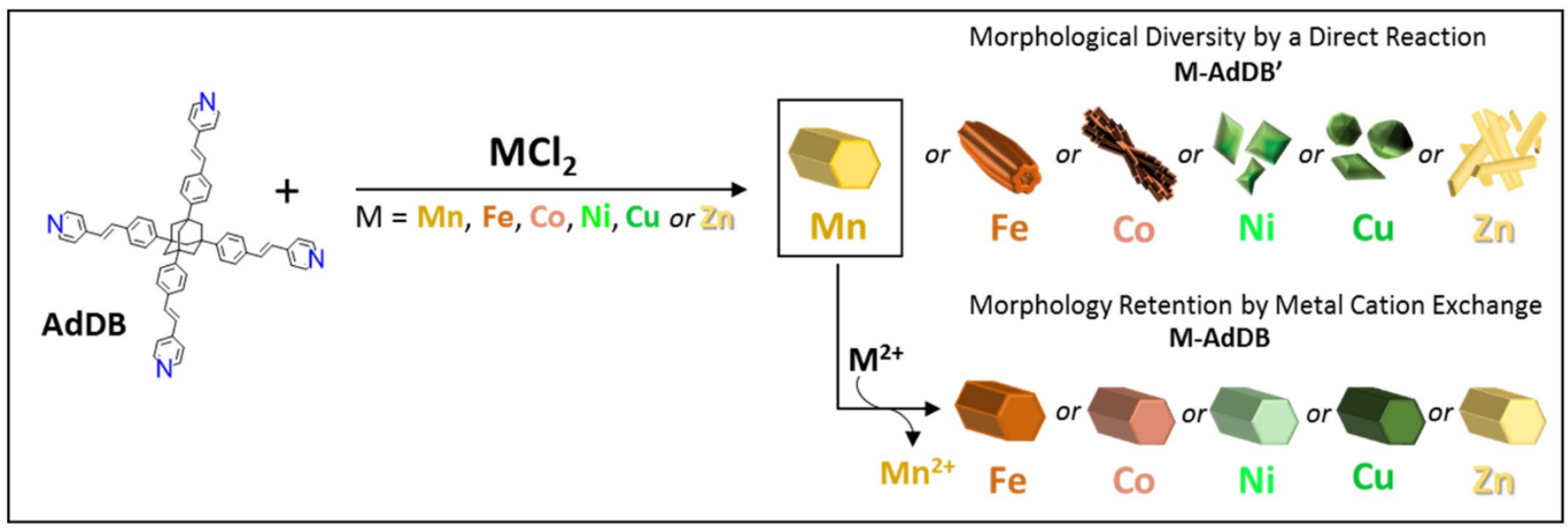

Scheme 1. Reaction of the tetrahedral pyridyl ligand, AdDB, with divalent first-row transition metal salts by layering of solvents (top row). The exchange of metal cations, starting from the metal-organic framework (MnAdDB), occurs with retention of the morphological uniformity (bottom row).

predict crystal morphology and elemental composition (from $\mathrm{Mn}^{2+}$ to $\mathrm{Fe}^{2+}, \mathrm{Co}^{2+}, \mathrm{Ni}^{2+}, \mathrm{Cu}^{2+}$ to $\mathrm{Zn}^{2+}$ ). Interestingly, the porosity of the crystallographic structure facilitates the formation of the new materials. The incoming cations use the continuous channels running throughout the crystal to reach the nodes. This mechanistic aspect was demonstrated by cutting (microtoming) the crystals and mapping the elemental composition within the structures, namely, the $\mathrm{Mn}^{2+}$ to $\mathrm{Cu}^{2+}$ exchange, by energy-dispersive X-ray spectroscopy (EDS) combined with scanning electron microscopy measurements (SEM). The versatility of the cation metathesis can be demonstrated also by a consecutive $\mathrm{Mn}^{2+}$ to $\mathrm{Co}^{2+}$ to $\mathrm{Cu}^{2+}$ exchange. The direct reaction of the tetrahedral pyridyl ligand with the diverse metal salts, under the same conditions, had resulted in different structures; however, by exploiting single-crystal to single-crystal conversion we have generated new MOF structures that preserve their unique crystallographic structures, i.e have two different nanochannels. Moreover, the materials obtained by cation metathesis maintain the hexagonal prism morphology of the starting Mn-based MOFs.

\section{RESULTS AND DISCUSSION}

Growth of the primary MOFs. The organic ligand AdDB $^{49,50}$ used here has a tetrahedral $\left(T_{d}\right)$ geometry, an adamantane core, and four phenyl-vinyl moieties for coordination to metal cations (Scheme 1). A solution of AdDB (1 eq) in chloroform (1.0 mL) was filtered and added to a glass tube $(\varnothing=10 \mathrm{~mm})$, followed by the addition of methanol ( 0.5 $\mathrm{mL}$ ), forming two distinct layers. Then, a solution of $\mathrm{MnCl}_{2} \cdot 2 \mathrm{H}_{2} \mathrm{O}$ (3 eq) in methanol (1.o mL) was added, forming a third, well-separated layer. The tube was sealed and tilted $\left(70^{\circ}\right.$ from the base) to enlarge the contact areas between the layers. Crystals were observed on the walls after $6 \mathrm{~h}$ by the naked eye and allowed to grow for another $42 \mathrm{~h}$. Light microscopy revealed the formation of hexagonal col- orless prisms (Figure 1, left). Scanning electron microscopy (SEM) imaging confirmed the structural features of Mn-AdDB, namely, having smooth surfaces and sharp edges $($ width $=10-30 \mu \mathrm{m}$, length $=10-80 \mu \mathrm{m})$ (Figure $\mathbf{1}$, right).

A single-crystal X-ray diffraction (SCXRD) study of MnAdDB unambiguously revealed the formation of a MOF (Figures 2, S1 and Table S2). The crystal structure consists of a rarely seen space group P622, ${ }^{45-48,51-57}$ which is one of the 65 Sohncke groups. This space group indicates a chiral packing, although the molecular building blocks are achiral. The divalent metal centers are coordinated to four pyridine moieties of four different ligands and have two $\mathrm{Cl}$ anions that form an octahedral geometry. The pyridine moieties are arranged in a "propeller"-like structure. All six $\mathrm{Mn}(\mathrm{pyr})_{4}$ coordination nodes in the unit cell have the same handiness. The Mn-N distances of 2.244(9) $\AA$, 2.264(10) $\AA$, and those of $\mathrm{Mn}-\mathrm{Cl}(2.536(3) \AA)$ are well within the ranges normally found for $\mathrm{MnX}_{2}(\mathrm{pyr})_{4}\left(\mathrm{X}=\right.$ halide). ${ }^{58,59}$ Another interesting structural aspect is the presence of two different chiral channels spanning the $c$ axis and having

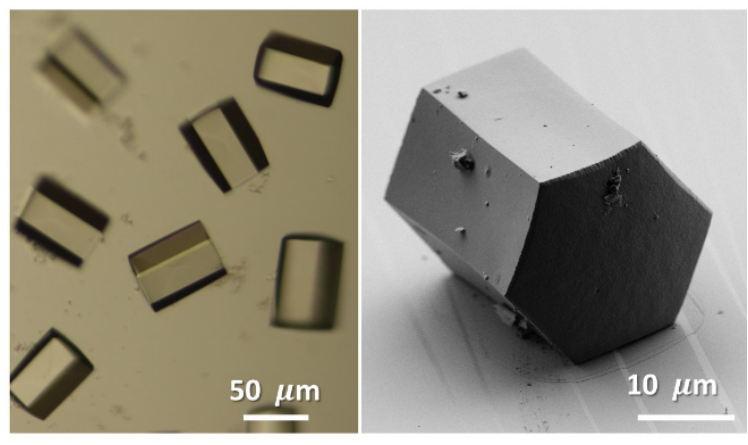

Figure 1. Optical microscope (left) and scanning electron microscope (right) images of Mn-AdDB. 


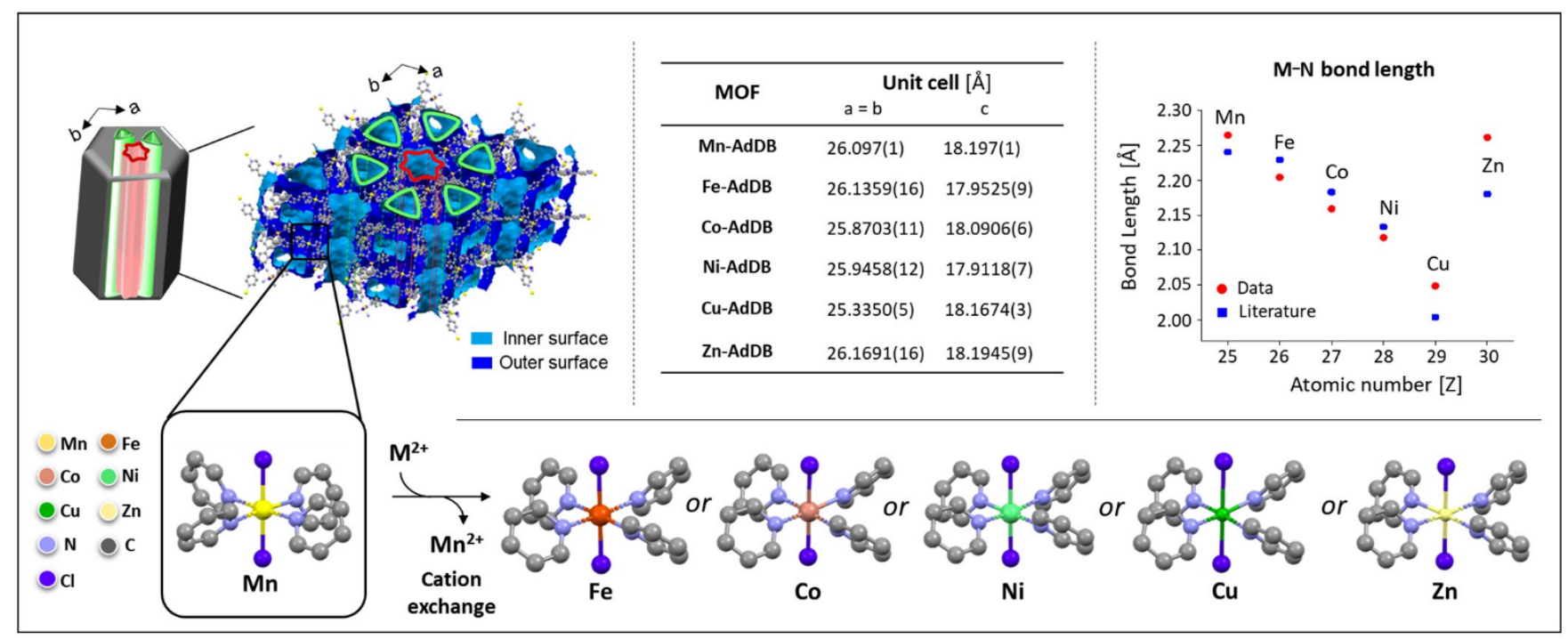

Figure 2. Selected single-crystal X-ray diffraction data of Mn-AdDB and the five metal-organic frameworks (MOFs) formed by metal cation exchange $\left(\mathrm{M}^{2+}=\mathrm{Fe}^{2+}, \mathrm{Co}^{2+}, \mathrm{Ni}^{2+}, \mathrm{Cu}^{2+}\right.$, and $\left.\mathrm{Zn}^{2+}\right)$. The crystallographic structures have the same hexagonal space group (P622). Two helicoidal nanochannels span along the $c$ axis with $\varnothing \approx 0.9 \mathrm{~nm}$ (red) and $1.2 \mathrm{~nm}$ (green). The unit cell dimensions are listed in the table. The graph summarizes the observed $\mathrm{M}-\mathrm{N}$ bond distances of the MOFs (red dots) with literature values (blue square) for corresponding mononuclear complexes surrounded by monodentate pyridine ligands, i.e., $\operatorname{trans}^{-}\left[\mathrm{MCl}_{2}(\mathrm{pyridine})_{4}\right]^{\mathrm{n}+} \cdot{ }^{59^{-}}$ ${ }^{62}$ Each unit cell contains six propeller-like coordination nodes with the same handiness. The single crystal X-ray data and structure refinement parameters are summarized in Tables S2-S6 and Figure S1.

diameters of $0.9 \mathrm{~nm}$ (red) and $1.2 \mathrm{~nm}$ (green). The chirality of these channels is evident in the constitutive helicoidally motifs. The inner walls of both channels are formed by helices with the same handiness, making the channels homochiral. The structure contains large solvent accessible voids (38.3\% of the total volume, calculated by Mercury CSD 2020.1.1, employing the contact surface and a spherical probe with a radius of $1.2 \AA$ ).

Metal cation exchange. Under identical growth conditions for the formation of Mn-AdDB, the use of AdDB with other transition metals, namely, $\mathrm{FeCl}_{2}, \mathrm{CoCl}_{2}, \mathrm{NiCl}_{2}, \mathrm{CuCl}_{2}$, and $\mathrm{ZnCl}_{2}$, resulted in undefined structures, as shown by SEM imaging (Figure 3, top row). Therefore, we used crystals of Mn-AdDB as a primer to exchange the cations while maintaining the morphological uniformity. The mother solution of Mn-AdDB was removed and a methanol solution was added containing one of the abovementioned metal salts. Visually, the bulk materials undergo a clear color change within $48 \mathrm{~h}$, as a first indication of a cation exchange process (Figure 4). Light microscopy revealed (i) preservation of the crystal morphology and dimensions, and (ii) the new colors, i.e., green (copper and nickel), orange (iron), and pink (cobalt) (Figure S2). Dissolution and recrystallization processes were not observed by in-situ imaging during this time. SEM images confirmed the preservation of the primary prism morphology (Figure 3, bottom

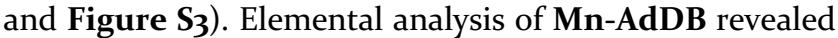
a composition identical to the formula derived from

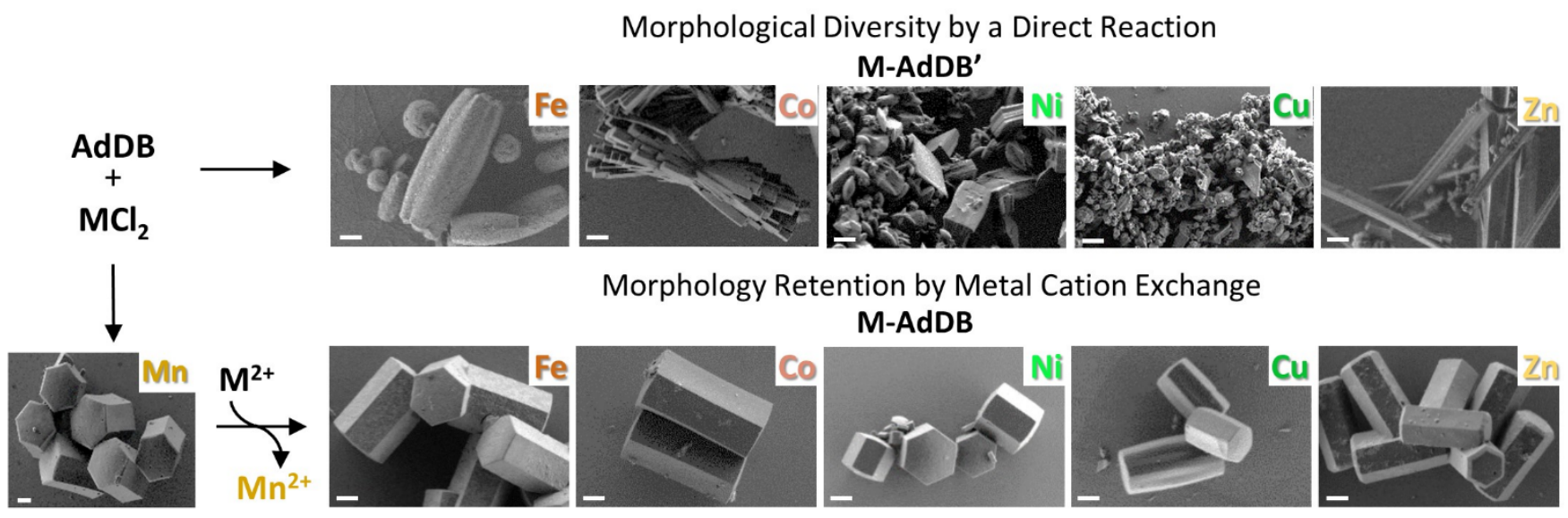

Figure 3. Scanning electron microscope images. Top row: Structures obtained by reactions of the tetrahedral pyridyl ligand AdDB, with metal dichloride salts by layering of solvents. Bottom row: Structures observed after exposing the metal-organic framework (Mn-AdDB) to methanol solutions containing a metal salt. $\mathrm{MCl}_{2}=\mathrm{Fe}^{2+}, \mathrm{Co}^{2+}, \mathrm{Ni}^{2+}, \mathrm{Cu}^{2+}$, and $\mathrm{Zn}^{2+}$. 


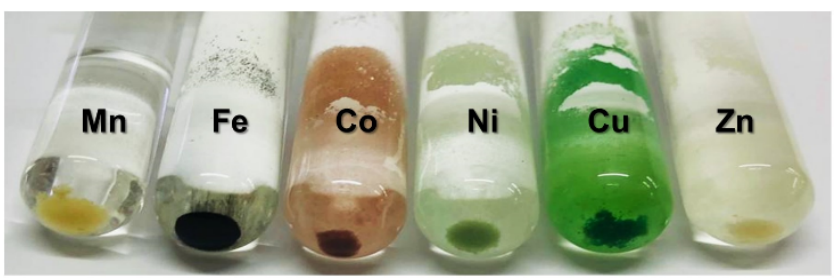

Figure 4. Photograph showing the colors of metal-organic frameworks (MOFs) before (left tube) and after exposing MnAdDB to methanol solutions containing a metal salt $\left(\mathrm{MCl}_{2}\right.$, with $\mathrm{M}=\mathrm{Fe}^{2+}, \mathrm{Co}^{2+}, \mathrm{Ni}^{2+}, \mathrm{Cu}^{2+}$, or $\left.\mathrm{Zn}^{2+}\right)$.

SCXRD (Table Si). SCXRD measurements and structure refinements showed a crystal-to-crystal conversion by metal cation exchange at coordination nodes (Figure 2). The crystallographic packing is retained. The cation exchange of the individual crystals is in good agreement with elemental analysis of the bulk materials that display a quantitative exchange (>99.4\%) of the Mn centers with the cations of the abovementioned salts. The unit cell parameters vary slightly $(<3 \%)$. The $\mathrm{N}_{\mathrm{pyr}}$-metal bond distances follow the trends reported in the literature for related pyridine complexes. ${ }^{59^{-62}}$ The Flack parameters after the cation exchange remain low (Tables $\mathbf{S}_{2}-\mathbf{S 6}$ ), indicating that the enantiopurity of the single crystals is preserved. ${ }^{63}$
The bulk crystallinity is preserved after the cation exchange, as indicated by powder X-ray diffraction measurements and fitting with the SCXRD data (Figure $\mathbf{S}_{4}$ ). The estimated unit cell parameters are in excellent agreement with the experimental values listed in Figure 2. Low- valent metal complexes can be oxidized under the applied reaction conditions; therefore, we analyzed Fe-AdDB by Xray photoelectron spectroscopy (XPS) (Figure $\mathbf{S}_{5}$ ). We observed the typical peaks for $\mathrm{Fe}^{3+}$ at $711.5 \mathrm{eV}\left(2 \mathrm{p}_{3 / 2}\right)$ and 725.1 $\mathrm{eV}\left(2 \mathrm{p}_{1 / 2}\right)$, accompanied by two satellite peaks at $\sim 719.1 \mathrm{eV}$ and $\sim 733.5 \mathrm{eV} .{ }^{64,65}$ No signals indicating the presence of the manganese cations were observed, further confirming that the cation exchange process occurred. This observation also shows that the exchange can be accompanied by a change in the oxidation state of the incoming metal cation. The Mn-to-Cu exchange was followed in-situ by light microscopy (Figure S6) and by ex-situ SEM combined with energy-dispersive X-ray spectroscopy (EDS) measurements over 2 days. Immediately upon the addition of a light green solution containing $\mathrm{CuCl}_{2}$ to $\mathbf{M n - A d D B}$, the colorless crystals turned green, as observed by the naked eye, along with a concurrent decrease in the color of the solution. No color changes were evident after 6 hours. Relatively dark bands were observed parallel to the bases.
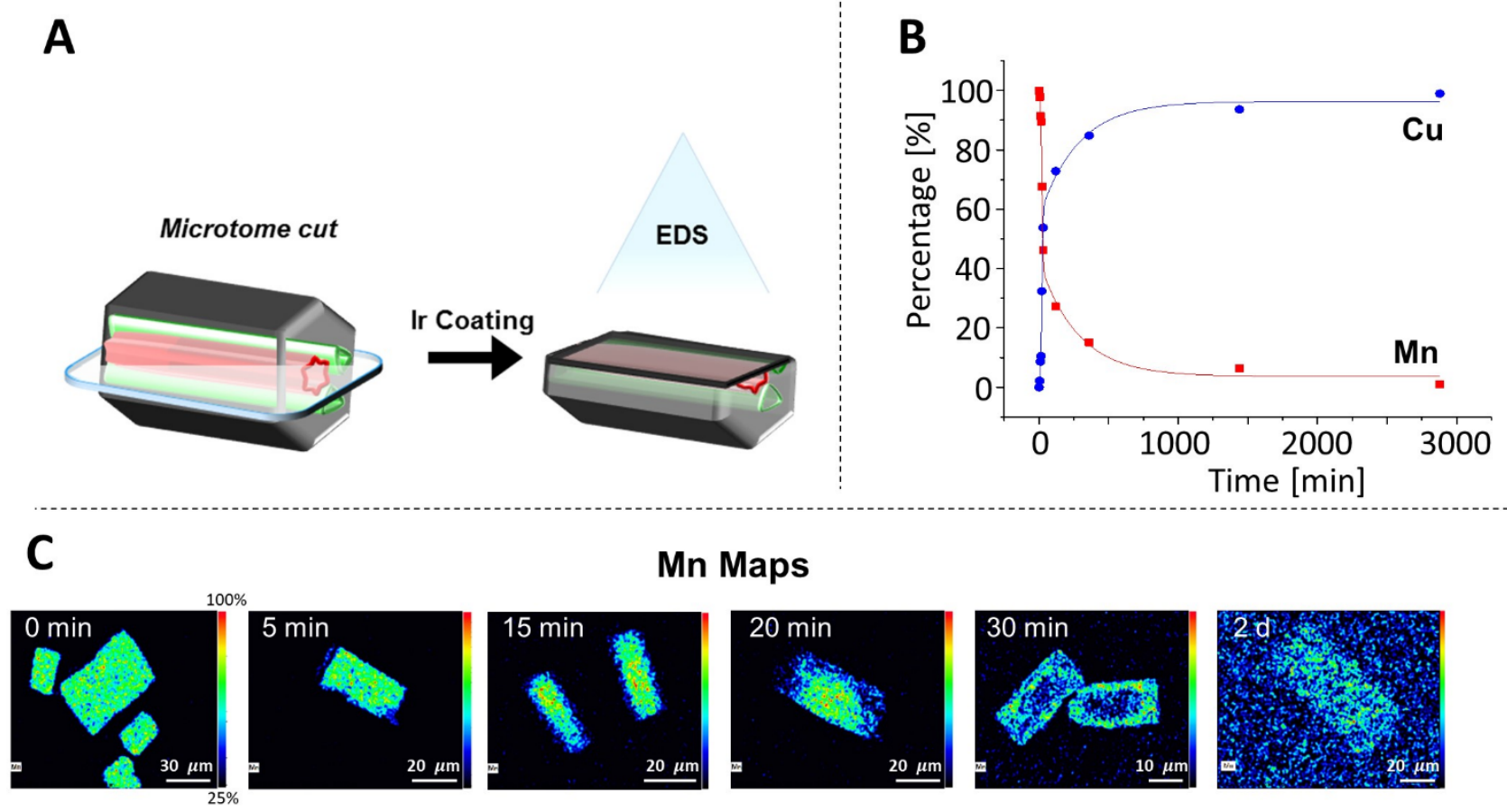

Mn Maps
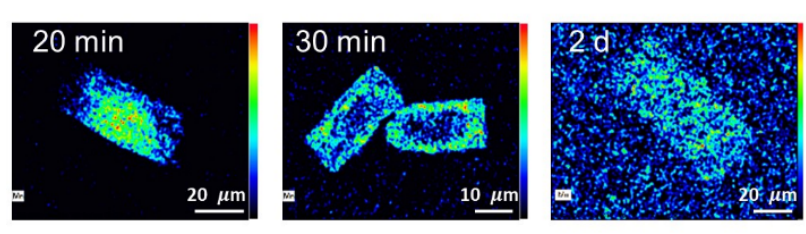

\section{Cu Maps}
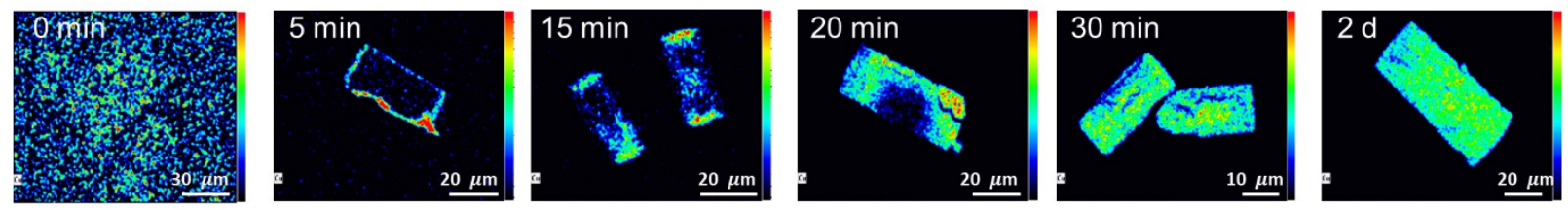

Figure 5. (A) Scheme showing the direction of the sectioning of Mn-AdDB by microtome, followed by coating with a thin layer of metallic iridium prior to elemental mapping by energy-dispersive X-ray spectroscopy (EDS). (B) Graph showing the relative quantities of manganese versus copper inside the crystals as a function of time. (C) EDS elemental intensity maps of metal cation content inside the crystals as a function of time. 

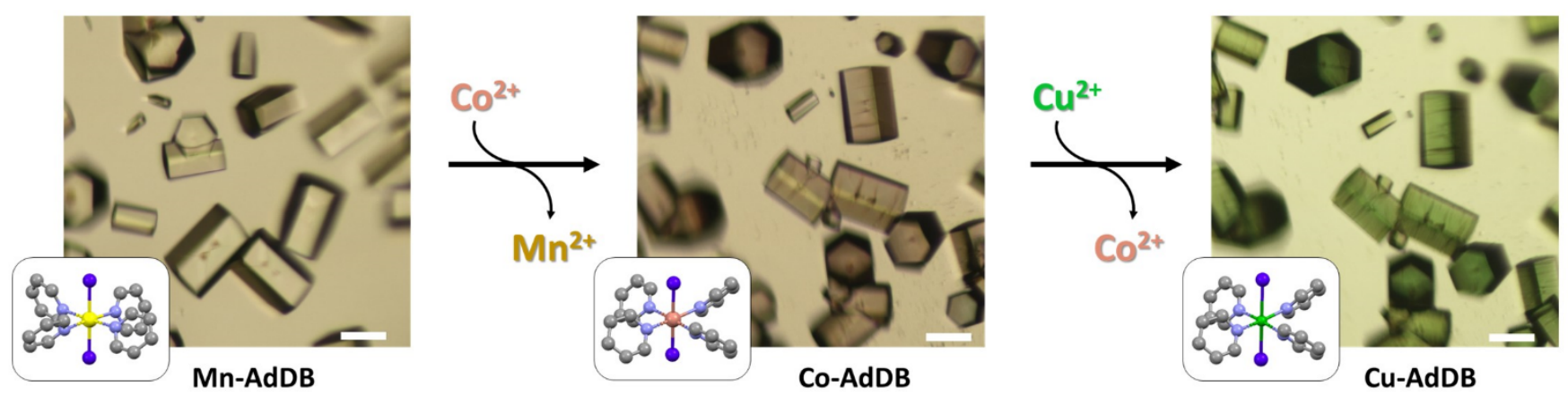

Figure 6. Consecutive cation exchange from Mn-AdDB to Co-AdDB, followed by the formation of Cu-AdDB. The images were obtained by optical microscopy. The insets show the metal coordination nodes from single-crystal X-ray diffraction (SCXRD) analysis. Color legend: yellow $=\mathrm{Mn}$; pink $=\mathrm{Co}$; green $=\mathrm{Cu}$, blue $=\mathrm{Cl}$; purple $=\mathrm{N}$; gray $=\mathrm{C}$.

Similar observations were made for the Mn-to-Fe and Mnto-Co exchange. These darker areas are probably due to light scattered by surface irregularities. Such surface features are also indicated by SEM and light microscopy images (Figure $\mathbf{S}_{\mathbf{7}}$ ).The elemental composition inside the crystals during the cation exchange was determined by time-dependent SEM-EDS analysis (Figure 5). Samples of the crystals on a silicon wafer were sliced with a microtome to observe exchange processes inside the materials. Then, the cut crystals were covered with a thin layer of iridium to eliminate charging effects. The spatial information provided by color maps revealed that the $\mathrm{Cu}^{2+}$ cations accumulate at all the crystal faces $(\mathrm{t}=5 \mathrm{~min})$. Then, $\mathrm{Cu}^{2+}$ mainly enters the crystals from the hexagonal basal (ool) face, with a coinciding decrease in the amount of $\mathrm{Mn}^{2+}(t=15-20$ min). Concurrently, the $\mathrm{Mn}^{2+}$ ions seem to diffuse from the center of the crystals to the hexagonal (oo1) face. After two days, only traces of $\mathrm{Mn}^{2+}$ remain. The overall process indicates that the channels direct the metal ion diffusion processes. EDS spectra of the cut crystals provided quantitative information about the elemental composition. Full cation exchange was observed after $\sim 2$ days, with $\mathrm{t}_{1 / 2} \approx 30$ min. We also demonstrated consecutive cation exchange from Mn-AdDB to Co-AdDB and subsequently from CoAdDB to Cu-AdDB (Figure 6). This experiment was performed by replacing only the solutions containing the metal salts. The complete exchange for both steps was confirmed by SCXRD and light microscopy. In-situ light microscopy showed intact crystals changing color from colorless to pink to green, as expected for the presence of $\mathrm{Mn}$, $\mathrm{Co}$, or $\mathrm{Cu}$, respectively. These experiments show that both morphology and crystal packing are preserved even upon multiple metal exchanges.

\section{CONCLUSIONS}

We have demonstrated that pyridine-based MOFs formed by tetrahedral linkers are suitable for quantitative metal cation exchange with retention of both their crystallinity and morphology. The exchange process is accompanied by changes in the optical properties of the crystals. The use of tetratopic linkers for such single-crystal to single-crystal conversion is rare. An example of metal cation exchange with a tetratopic and planar carbocyclic acid-based ligand was recently reported by Kaskel and co-workers. ${ }^{66}$ However, tetrahedral linkers, as reported in this study, have not been used. Such non-planar ligands are especially interesting because of their propensity to form highly complex and chiral structures that contain continuous channels. ${ }^{45-48,67}$ Although all facets of the crystals are accessible to the incoming metal cations, the exchange process proceeds along the direction of these channels. This observation indicates that the channels facilitate the diffusion of the metal cations in-and-out of the crystal structure. The crystal structure analysis of the initial crystals reveals coordinatively saturated metal centers, strongly indicating that the exchange processes involve pyridine-metal dissociation steps prior to the exchange processes. Although speculative, the role of defects cannot be excluded. ${ }^{57}$ Binding of incoming cations might induce stress that results in destabilization of adjacent metal-coordination sites. Such proposed dynamic behavior is more likely to occur with pyridine linkers that have a moderate ligand field strength than with hard ligands such as carboxylic acids. ${ }^{36}$

\section{EXPERIMENTAL SECTION}

Materials and Methods. 1-Bromoadmantane (99\%), benzene (99.7\%), $\mathrm{AlCl}_{3}$, iodine, bis(triphenylphosphine)palladium(II)dichloride, 4-vinylpyridine (95\%), $\mathrm{CuCl}_{2}$ (97\%), $\mathrm{CoCl}_{2} \cdot 6 \mathrm{H}_{2} \mathrm{O}$ (98\%), and N-methyl-2-pyrrolidone (NMP) were purchased from Sigma Aldrich. The following compounds were also purchased: t-butylbromide (Apollo), bis(trifluoroacetoxy)iodo)benzene (Fluka Chemika), chloroform $\left(\mathrm{CHCl}_{3}, \geq 99.8 \%\right.$ ) (Bio-Lab), triethylamine (Alfa Aesar), diethyl ether (Bio-Lab), dimethylformamide (DMF, $\geq 99.8 \%$ ) (Alfa Aesar), $\mathrm{FeCl}_{2} \cdot 4 \mathrm{H}_{2} \mathrm{O}$ (98\%) (Alfa Aesar), $\mathrm{MnCl}_{2} \cdot 2 \mathrm{H}_{2} \mathrm{O}$ (Merck, $\geq 99 \%$ ), $\mathrm{NiCl}_{2} \cdot 6 \mathrm{H}_{2} \mathrm{O}$ (97\%) (BDH - laboratory reagents), and $\mathrm{ZnCl}_{2}$ (98\%) (Fluka). Reagents were used without further purification. Glass pressure tubes (Ace Glass, Inc., pressure tubes \#15 with a plunger valve, PTFE Bushing and FETFE ${ }^{\circledR}$ O-Ring, volume $50 \mathrm{~mL}$ ) 
were cleaned by immersion in a base bath (1.5 $\mathrm{M}, \mathrm{NaOH})$ for 2 to 3 days, then washed with water and ethanol. The preparation of 1,3,5,7-tetrakis\{4-[(E)-2-pyridine-4-yl-vinyl]phenyl \}admantane (AdDB) was carried out according to a literature procedure. ${ }^{49,50}$

Preparation of Mn-AdDB. The crystals were obtained by layering solvents in a tube of borosilicate glass $(\varnothing=10 \times 75$ $\mathrm{mm}, 4 \mathrm{~mL}$ volume) at room temperature. A solution of AdDB (3.5 mg, $4.1 \mu \mathrm{mol}, 3.5 \mathrm{mg} / \mathrm{mL}, 1 \mathrm{eq})$ in chloroform (1.0 $\mathrm{mL}$ ) was filtered using cotton and injected into the tube. A layer of methanol ( $0.5 \mathrm{~mL}$ ) was added on top of the chloroform. Then, a layer of $\mathrm{MnCl}_{2} \cdot 2 \mathrm{H}_{2} \mathrm{O}$ (2.0 mg, 12.3 $\mu \mathrm{mol}$, $2.0 \mathrm{mg} / \mathrm{mL}, 3 \mathrm{eq})$ in methanol (1.0 mL) was placed on the layer of methanol. The tube was sealed, tilted $\left(70^{\circ}\right.$ from the base) without mixing the solvents, to enlarge the contact areas between the layers by $\sim 3 X$ in order to facilitate the diffusion process. The formation of colorless hexagon crystals was observed after $6 \mathrm{~h}$ by a light microscope (length: 10-80, width: 10-30). The crystals were left in the mother solution at room temperature. The yield of MnAdDB was 48\%.

Direct preparation of Fe-AdDB', Co-AdDB', Ni-AdDB', Cu-AdDB', and Zn-AdDB'. The samples were obtained by layering solvents in a borosilicate glass tube $(\varnothing=10 \times 75$ mm, $4 \mathrm{~mL}$ ) at room temperature. For Fe-AdDB', a solution of AdDB (4.5 mg, $5.3 \mu \mathrm{mol}, 4.5 \mathrm{mg} / \mathrm{mL}$, 1 eq) in chloroform (1.0 mL) was filtered using cotton and injected into the tube. A layer of methanol $(0.5 \mathrm{~mL})$ was added on top of the layer of chloroform. Then, a layer of the metal salt, $\mathrm{FeCl}_{2} \cdot 4 \mathrm{H}_{2} \mathrm{O}$ (2.0 mg, $15.8 \mu \mathrm{mol}$, $2.0 \mathrm{mg} / \mathrm{mL}$, $3 \mathrm{eq}$ ) in methanol (1.0 mL), was placed on top of the layer of methanol. The tube was sealed and tilted ( $70^{\circ}$ from the base) to enlarge the contact areas between the layers, in order to facilitate the diffusion process. After $6 \mathrm{~h}$, an orange powder appeared on the tube wall. The same procedure was used for forming the other crystals. Co-AdDB': AdDB $(2.4 \mathrm{mg}$, $2.8 \mu \mathrm{mol}, 2.4 \mathrm{mg} / \mathrm{mL}, 1 \mathrm{eq}$ ), $\mathrm{CoCl}_{2} \cdot 6 \mathrm{H}_{2} \mathrm{O}$ (2.0 mg, $8.4 \mu \mathrm{mol}$, $2.0 \mathrm{mg} / \mathrm{mL}, 3 \mathrm{eq}$ ). Ni-AdDB': AdDB (2.4 mg, $2.8 \mu \mathrm{mol}, 2.4$ $\mathrm{mg} / \mathrm{mL}, 1 \mathrm{eq}), \mathrm{NiCl}_{2} \cdot 6 \mathrm{H}_{2} \mathrm{O}$ (2.0 mg, $8.4 \mu \mathrm{mol}, 2.0 \mathrm{mg} / \mathrm{mL}, 3$ eq). Cu-AdDB': AdDB (4.2 mg, $4.9 \mu \mathrm{mol}, 4.2 \mathrm{mg} / \mathrm{mL}, 1 \mathrm{eq})$, $\mathrm{CuCl}_{2}$ (2.0 mg, $\left.14.8 \mu \mathrm{mol}, 2.0 \mathrm{mg} / \mathrm{mL}, 3 \mathrm{eq}\right)$. Zn-AdDB': AdDB (3.3 mg, $3.9 \mu \mathrm{mol}, 3.3 \mathrm{mg} / \mathrm{mL}$, 1 eq), $\mathrm{ZnCl}_{2}$ (2.0 mg, $14.6 \mu \mathrm{mol}, 2.0 \mathrm{mg} / \mathrm{mL}, 3 \mathrm{eq})$ were used. The resulting materials have the following colors: Co-AdDB', pink; NiAdDB', light green; Cu-AdDB', green; and Zn-AdDB' colorless.

Crystal-to-Crystal Conversion by Exchange of $\mathrm{Mn}^{2+}$ by $\mathrm{Fe}^{2+}, \mathrm{Co}^{2+}, \mathrm{Ni}^{2+}, \mathrm{Cu}^{2+}$, and $\mathrm{Zn}^{2+}$. After the formation of $\mathrm{Mn}-$ AdDB, the mother liquid was removed with a syringe from the tube. Subsequently, a freshly prepared solution of $\mathrm{FeCl}_{2} \cdot 4 \mathrm{H}_{2} \mathrm{O}(1.6 \mathrm{~g}, 8.2 \mathrm{mmol}, 400 \mathrm{mg} / \mathrm{mL}), \mathrm{CoCl}_{2} \cdot 6 \mathrm{H}_{2} \mathrm{O}(1.9$ g, $8.2 \mathrm{mmol}, 485 \mathrm{mg} / \mathrm{mL}), \mathrm{NiCl}_{2} \cdot 6 \mathrm{H}_{2} \mathrm{O}(1.9 \mathrm{~g}, 8.2 \mathrm{mmol}, 484$ $\mathrm{mg} / \mathrm{mL}$ ), $\mathrm{CuCl}_{2}$ (15 mg, o.11 mmol, $3.8 \mathrm{mg} / \mathrm{mL}$ ), or $\mathrm{ZnCl}_{2}$ (15.6 mg, $1.15 \mathrm{mmol}, 3.9 \mathrm{mg} / \mathrm{mL}$ ) in methanol $(4.0 \mathrm{~mL})$ was slowly added to the tube. The tube was sealed by Parafilm, tilted ( $70^{\circ}$ from the base), and left at room temperature for two days. Subsequently, the solution was removed by a syringe. The colorless crystals left in a solution containing $\mathrm{CuCl}_{2}$ gradually became green. For the crystals immersed in solutions containing $\mathrm{FeCl}_{2} \cdot 4 \mathrm{H}_{2} \mathrm{O}, \mathrm{CoCl}_{2} \cdot 6 \mathrm{H}_{2} \mathrm{O}$, and $\mathrm{NiCl}_{2} \cdot 6 \mathrm{H}_{2} \mathrm{O}$, the intense color of the solutions prevented observing changes in the color of the crystals during the experiment. After isolation, the crystals appeared orange $\left(\mathrm{FeCl}_{2} \cdot 4 \mathrm{H}_{2} \mathrm{O}\right)$, pink $\left(\mathrm{CoCl}_{2} \cdot 6 \mathrm{H}_{2} \mathrm{O}\right)$, and light green $\left(\mathrm{NiCl}_{2} \cdot 6 \mathrm{H}_{2} \mathrm{O}\right)$. The crystals remained colorless after the $\mathrm{Mn}^{2+}$ to $\mathrm{Zn}^{2+}$ exchange. Finally, the crystals were isolated, washed with methanol $(4 X)$, and were stable at room temperature in methanol for six months.

Consecutive Crystal-to-Crystal Conversion by Metal Cation Exchange of $\mathrm{Mn}^{2+}$ by $\mathrm{Co}^{2+}$, followed by the Exchange of $\mathrm{Co}^{2+}$ by $\mathrm{Cu}^{2+}$. After the formation of Mn-AdDB, the mother liquid was removed with a syringe from the glass tube. Subsequently, a freshly prepared solution of $\mathrm{CoCl}_{2} \cdot 6 \mathrm{H}_{2} \mathrm{O}$ (1.9 g, $8.2 \mathrm{mmol}, 485 \mathrm{mg} / \mathrm{mL}$ ) in methanol (4.0 $\mathrm{mL}$ ) was slowly added to the tube. The tube was sealed by Parafilm, tilted ( $70^{\circ}$ from the base), and left at room temperature for 2 days. Subsequently, the solution was removed by a syringe. Then, the crystals were washed four times using methanol. This step concludes the first metal exchange process; pink crystals of Co-AdDB were formed, as shown by SCXRD. The same sample of Co-AdDB was then immersed in a solution of $\mathrm{CuCl}_{2}(52.1 \mathrm{mg}, 8.2 \mathrm{mmol}$, $13.0 \mathrm{mg} / \mathrm{mL}$ ) in methanol $(4.0 \mathrm{~mL})$. The tube was sealed by Parafilm, tilted ( $70^{\circ}$ from the base), and left at room temperature for 2 days without external modifications. The sample underwent identical solvent removal and crystal washing processes as those previously described for the first metal exchanging process. This step concludes the second metal exchange process; green crystals of $\mathbf{C u}$ AdDB were formed, as shown by light microscopy and SCXRD. These MOFs were stored in methanol solution at room temperature in a sealed tube for at least six months.

\section{ASSOCIATED CONTENT}

\section{Supporting Information}

The Supporting Information is available free of charge via the Internet at http://pubs.acs.org. Descriptions of the methods, elemental analysis of the bulk samples, single crystal X-ray data and structure refinement parameters, additional SEM and optical images, powder X-ray diffraction spectra and fits, $\mathrm{X}$-ray Photoelectron spectra.

\section{Accession Codes}

CCDC 2024341-2024345, 2078970-2078973, 2078788 contain the supplementary crystallographic data for this paper. These data can be obtained free of charge via www.ccdc.cam.ac.uk/data_request/cif, or by emailing data_request@ccdc.cam.ac.uk, or by contacting The Cambridge Crystallographic Data Centre, 12 Union Road, Cambridge CB2 1EZ, UK; fax: +44 1223336033. 


\section{AUTHOR INFORMATION}

\section{Corresponding Authors}

* Michal Lahav-Department of Molecular Chemistry and Material Science, Weizmann Institute of Science, 7610001 Rehovot, Israel.

Email: michal.lahav@weizmann.ac.il

* Milko E. van der Boom - Department of Molecular Chemistry and Material Science, Weizmann Institute of Science, 7610001 Rehovot, Israel.

Email: milko.vanderboom@weizmann.ac.il

\section{Authors}

Hadar Nasi - Department of Molecular Chemistry and Material Science, Weizmann Institute of Science, 7610001 Rehovot, Israel.

Maria Chiara di Gregorio - Department of Molecular Chemistry and Material Science, Weizmann Institute of Science, 7610001 Rehovot, Israel.

Qiang Wen - Department of Molecular Chemistry and Material Science, Weizmann Institute of Science, 7610001 Rehovot, Israel.

Linda J. W. Shimon - Department of Chemical Research Support, Weizmann Institute of Science, 7610001 Rehovot, Israel.

Ifat Kaplan-Ashiri - Department of Chemical Research Support, Weizmann Institute of Science, 7610001 Rehovot, Israel.

Tatyana Bendikov - Department of Chemical Research Support, Weizmann Institute of Science, 7610001 Rehovot, Israel.

\section{Funding Sources}

This research was supported by the Irving and Cherna Moskowitz Center for Nano and Bioimaging at the Weizmann Institute of Science, the Israel Science Foundation (ISF) and the Minerva Foundation.

\section{ACKNOWLEDGMENT}

We thank Dr. Eyal Shimoni for sample preparation for the EDS measurements and Dr. Yishay Feldman for his assistance with the PXRD analysis. M.E.v.d.B. holds the Bruce A. Pearlman Professional Chair in Synthetic Organic Chemistry.

\section{ABBREVIATIONS}

MOF, metal-organic framework; AdDB, 1,3,5,7-tetrakis $\left\{4^{-}\right.$ [(E)-2-pyridine-4-yl-vinyl]phenyl \}admantane; SCXRD, singlecrystal X-ray diffraction; SEM, scanning electron microscopy; EDS, energy-dispersive X-ray spectroscopy; XPS, X-ray photoelectron spectroscopy.

\section{REFERENCES}

(1) Hosseini, M. I. R. W. Molecular Tectonics: From Simple Tectons to Complex Molecular Networks Inclusion Networks : An Interplay Between. Acc. Chem. Res. 2005, 38, 313-323.

(2) Yano, K.; Itoh, Y.; Araoka, F.; Watanabe, G.; Hikima, T.; Aida, T. Nematic-to-Columnar Mesophase Transition by in situ Supramolecular Polymerization. Science. 2019, 363, 161-165.

(3) Zhan, C.; Cameron, J. M.; Gabb, D.; Boyd, T.; Winter, R. S.; Vila-Nadal, L.; Mitchell, S. G.; Glatzel, S.; Breternitz, J.; Gregory, D. H.; Long, D.; Macdonell, A.; Cronin, L. A Metamorphic Inorganic Framework That Can Be Switched between Eight SingleCrystalline States. Nat. Commun. 2017, 8, 14185.
(4) Fernandez-Palacio, F.; Poutanen, M.; Saccone, M.; Siiskonen, A.; Terraneo, G.; Resnati, G.; Ikkala, O.; Metrangolo, P.; Priimagi, A. Efficient Light-Induced Phase Transitions in Halogen-Bonded Liquid Crystals. Chem. Mater. 2016, 28, 8314-8321.

(5) Zhang, F.-L.; Chen, J.-Q.; Qin, L.-F.; Tian, L.; Li, Z.; Ren, X.; Gu, Z.-G. Metal-Center Exchange of Tetrahedral Cages: Single Crystal to Single Crystal and Spin-Crossover Properties. Chem. Commun. 2016, 52, 4796-4799.

(6) Kahr, B.; Ward, M. D. Stressed out Crystals. Nat. Chem. 2018, 10, 4-6.

(7) Waller, P. J.; AlFaraj, Y. S.; Diercks, C. S.; Jarenwattananon, N. N.; Yaghi, O. M. Conversion of Imine to Oxazole and Thiazole Linkages in Covalent Organic Frameworks. J. Am. Chem. Soc. 2018, 140, 9099-9103.

(8) Dogan, S.; Kudera, S.; Dang, Z.; Palazon, F.; Petralanda, U.; Artyukhin, S.; De Trizio, L.; Manna, L.; Krahne, R. Lateral Epitaxial Heterojunctions in Single Nanowires Fabricated by Masked Cation Exchange. Nat. Commun. 2018, 9, 505.

(9) Son, D. H.; Hughes, S. M.; Yin, Y.; Alivisatos, A. P. Cation Exchange Reactions in Ionic Nanocrystals. Science. 2004, 306, 1009-1012.

(10) Hao, M.; Bai, Y.; Zeiske, S.; Ren, L.; Liu, J.; Yuan, Y.; Zarrabi, N.; Cheng, N.; Ghasemi, M.; Chen, P.; Lyu, M.; He, D.; Yun, J.; Du, Y.; Wang, Y.; Ding, S.; Armin, A.; Meredith, P.; Liu, G.; Cheng, H.; Wang, L. Ligand-Assisted Cation-Exchange Engineering for High-Efficiency Colloidal $\mathrm{Cs}_{\mathrm{s}_{-} \mathrm{x}} \mathrm{FA}_{\mathrm{x}} \mathrm{PbI}_{3}$ Quantum Dot Solar Cells with Reduced Phase Segregation. Nat. Energy 2020, 5, 7988.

(11) Trizio, L. De; Manna, L. Forging Colloidal Nanostructures via Cation Exchange Reactions. Chem. Rev. 2016, 116, 1085210887.

(12) Van der Stam, W.; Geuchies, J. J.; Altantzis, T.; Van Den Bos, K. H. W.; Meeldijk, J. D.; Van Aert, S.; Bals, S.; Vanmaekelbergh, D.; de Mello Donega, C. Highly Emissive Divalent-Ion-Doped Colloidal $\mathrm{CsPb}_{1-\mathrm{x}} \mathrm{M}_{\mathrm{x}} \mathrm{Br}_{3}$ Perovskite Nanocrystals through Cation Exchange. J. Am. Chem. Soc. 2017, 139, 4087-4097.

(13) Zhang, Y.; Lu, D.; Gao, M.; Lai, M.; Lin, J.; Lei, T.; Lin, Z.; Quan, L. N.; Yang, P. Quantitative Imaging of Anion Exchange Kinetics in Halide Perovskites. Proc. Natl. Acad. Sci. U.S.A. 2019, 116, 12648-12653.

(14) Sanchez-Iglesias, A.; Grzelczak, M.; Rodríguez-González, B.; Álvarez-Puebla, R. A.; Liz-Marzán, L. M.; Kotov, N. A. Gold Colloids with Unconventional Angled Shapes. Langmuir 20o9, 25, 11431-11435.

(15) Oh, M. H.; Yu, T.; Yu, S.-H.; Lim, B.; Ko, K.-T.; Willinger, M.-G.; Seo, D.-H.; Kim, B. H.; Cho, M. G.; Park, J.-H.; Kang, K.; Sung, Y.-E.; Pinna, N.; Hyeon, T. Galvanic Replacement Reactions in Metal Oxide Nanocrystals. Science. 2013, 340, 964-969.

(16) Anderson, B. D.; Tracy, J. B. Nanoparticle Conversion Chemistry: Kirkendall Effect, Galvanic Exchange, and Anion Exchange. Nanoscale 2014, 6, 12195-12216.

(17) Kreno, L. E.; Leong, K.; Farha, O. K.; Allendorf, M.; Duyne, R. P. Van; Hupp, J. T. Metal-Organic Framework Materials as Chemical Sensors Lauren. Chem. Rev. 2012, 112, 1105-1125.

(18) Xiao, B.; Wheatley, P. S.; Zhao, X.; Fletcher, A. J.; Fox, S.; Rossi, A. G.; Megson, I. L.; Bordiga, S.; Regli, L.; Thomas, K. M.; Morris, R. E. High-Capacity Hydrogen and Nitric Oxide Adsorption and Storage in a Metal-Organic Framework. J. Am. Chem. Soc. 2007, 129, 1203-1209.

(19) Zarra, S.; Wood, D. M.; Roberts, D. A.; Jonathan, N. R. Molecular Containers in Complex Chemical Systems. Chem. Rev. 2015, 44, 419-432.

(20) Takezawa, H.; Tabuchi, R.; Sunohara, H.; Fujita, M. Confinement of Water-Soluble Cationic Substrates in a Cationic Molecular Cage by Capping the Portals with Tripodal Anions. J. Am. Chem. Soc. 2020, 142, 17919-17922. 
(21) Mukherjee, G.; Biradha, K. Post-Synthetic Modification of Isomorphic Coordination Layers : Exchange Dynamics of Metal Ions in a Single Crystal to Single Crystal Fashion. Chem. Commun. 2012, 48, 4293-4295.

(22) Evans, J. D.; Sumby, C. J.; Doonan, C. J. Post-Synthetic Metalation of Metal-Organic Frameworks. Chem. Soc. Rev. 2014 43, 5933-5951.

(23) Zhao, C.; Dai, X.; Yao, T.; Chen, W.; Wang, X.; Wang, J.; Yang, J.; Wei, S.; Wu, Y.; Li, Y. Ionic Exchange of Metal-Organic Frameworks to Access Single Nickel Sites for Efficient Electroreduction of $\mathrm{CO}_{2}$. J. Am. Chem. Soc. 2017, 139, 8078-8081.

(24) Claire, F. J.; Solomos, M. A.; Kim, J.; Wang, G.; Siegler, M. A.; Crommie, M. F.; Kempa, T. J. Structural and Electronic Switching of a Single Crystal 2D Metal-Organic Framework Prepared by Chemical Vapor Deposition. Nat. Commun. 2020, 11, 5524 .

(25) Horike, S.; Shimomura, S.; Kitagawa, S. Soft Porous Crystals. Nat. Chem. 2009, 1, 695-704.

(26) Krause, S.; Hosono, N.; Kitagawa, S. Chemistry of Soft Porous Crystals : Structural Dynamics and Gas Adsorption Properties. Angew. Chem. Int. Ed 2020, 59, 15325-15341.

(27) Kalmutzki, M. J.; Hanikel, N.; Yaghi, O. M. Secondary Building Units as the Turning Point in the Development of the Reticular Chemistry of MOFs. Sci. Adv. 2018, 4, eaat918o.

(28) Dincă, M.; Long, J. R. High-Enthalpy Hydrogen Adsorption in Cation-Exchanged Variants of the Microporous Metal-Organic Framework $\mathrm{Mn}_{3}\left[\left(\mathrm{Mn}_{4} \mathrm{CI}\right)_{3}(\mathrm{BTT})_{8}\left(\mathrm{CH}_{3} \mathrm{OH}\right)_{1 \mathrm{o}}\right]_{2}$. J. Am. Chem. Soc. 2007, 129, 11172-11176.

(29) Evans D., J.; Bon, V.; Senkovska, I.; Lee, H.-C.; Kaskel, S. Four-Dimensional Metal-Organic Frameworks. Nat. Commun. 2020, 11, 2690.

(30) Carnes, M. E.; Collins, M. S.; Johnson, D. W. Transmetalation of Self-Assembled, Supramolecular Complexes. Chem. Soc. Rev. 2014, 43, 1825-1834.

(31) An, J.; Rosi, N. L. Tuning MOF $\mathrm{CO}_{2}$ Adsorption Properties via Cation Exchange. J. Am. Chem. Soc. 2o10, 132, 5578-5579.

(32) Abednatanzi, S.; Derakhshandeh, P. G.; Depauw, H.; Coudert, F.-X.; Vrielinck, H.; Van Der Voort, P.; Leus, K. MixedMetal Metal-Organic Frameworks. Chem. Soc. Rev. 2019, 48, 2535-2565.

(33) Song, X.; Jeong, S.; Kim, D.; Soo, M. L. Transmetalations in Two Metal-Organic Frameworks with Different Framework Flexibilities: Kinetics and Core - Shell Heterostructure. CrystEngComm 2012, 14, 5753-5756.

(34) Brozek, C. K.; Dincă, M. Cation Exchange at the Secondary Building Units of Metal-Organic Frameworks. Chem. Soc. Rev. 2014, 43, 5456-5467.

(35) Dodson, R. A.; Kalenak, A. P.; Matzger, A. J. Solvent Choice in Metal-Organic Framework Linker Exchange Permits Microstructural Control. J. Am. Chem. Soc. 2020, 142, 2080620813 .

(36) Hamisu, A. M.; Ariffin, A.; Wibowo, A. C. Cation Exchange in Metal-Organic Frameworks (MOFs): The Hard-Soft Acid- Base (HSAB) Principle Appraisal. Inorg. Chim. Acta. 2o2o, 511, 119801.

(37) Brozek, C. K.; Dincă, M. $\mathrm{Ti}^{3+}-, \mathrm{V}^{2+/ 3+}-, \mathrm{Cr}^{2+/ 3+}-, \mathrm{Mn}^{2+}$, and $\mathrm{Fe}^{2+}$-Substituted $\mathrm{MOF}_{-5}$ and Redox Reactivity in $\mathrm{Cr}-$ and $\mathrm{Fe}-$ MOF-5. J. Am. Chem. Soc. 2013, 135, 12886-12891.

(38) Das, S.; Kim, H.; Kim, O. Metathesis in Single Crystal: Complete and Reversible Exchange of Metal Ions Constituting the Frameworks of Metal-Organic Frameworks. J. Am. Chem. Soc. 2009, 131, 3814-3815.

(39) Mi, L.; Hou, H.; Song, Z.; Han, H.; Xu, H.; Fan, Y.; Ng, S. Rational Construction of Porous Polymeric Cadmium Ferrocene1,1'-Disulfonates for Transition Metal Ion Exchange and Sorption. Cryst. Growth Des. 2007, 7, 2553-2561.
(40) Yao, Q.; Sun, J.; Ki, K.; Su, J.; Peskov, M. V.; Zou, X. A Series of Isostructural Mesoporous Metal-Organic Frameworks Obtained by Ion-Exchange Induced Single-Crystal to Single-Crystal Transformation. Dalt. Trans. 2012, 41, 3953-3955.

(41) Lah, M. S.; Song, X.; Kim, T. K.; Kim, H.; Kim, D.; Jeong, S.; Moon, H. R. Post-Synthetic Modifications of Framework Metal Ions in Isostructural Metal-Organic Frameworks: Core - Shell Heterostructures via Selective Transmetalations. Chem. Mater. 2012, 24, 3065-3073.

(42) Burnett, B. J.; Barron, P. M.; Hu, C.; Choe, W. Stepwise Synthesis of Metal - Organic Frameworks: Replacement of Structural Organic Linkers. J. Am. Chem. Soc. 2o11, 133, 9984-9987.

(43) Xu, M.-M.; Chen, Q.; Xie, L.-H.; Li, J.-R. Exchange Reactions in Metal-Organic Frameworks: New Advances. Coord. Chem. Rev. 2020, 421, 213421.

(44) De, D.; Neogi, S.; Sanudo, E. C.; Bharadwaj, P. K. SingleCrystal to Single-Crystal Linker Substitution, Linker Place Exchange, and Transmetalation Reactions in Interpenetrated Pillared - Bilayer Zinc(II) Metal-Organic Frameworks. Chem. - A Eur. J. 2015, 21, 17422-17429.

(45) di Gregorio, M. C.; Elsousou, M.; Wen, Q.; Shimon, L. J. W.; Brumfeld, V.; Houben, L.; Lahav, M.; van der Boom, M. E. Molecular Cannibalism: Sacrificial Materials as Precursors for Hollow and Multidomain Single Crystals. Nat. Commun. 2021, $12,957$.

(46) Wen, Q.; Tenenholtz, S.; Shimon, L. J. W.; Bar-Elli, O.; Beck, L. M.; Houben, L.; Cohen, S. R.; Feldman, Y.; Oron, D.; Lahav, M.; van der Boom, M. E. Chiral and SHG-Active Metal-Organic Frameworks Formed in Solution and on Surfaces: Uniformity, Morphology Control, Oriented Growth, and Postassembly Functionalization. J. Am. Chem. Soc. 2020, 142, 14210-14221.

(47) Singh, V.; Houben, L.; Shimon, L. J. W.; Cohen, S. R.; Golani, O.; Feldman, Y.; Lahav, M.; van der Boom, M. E. Crystal Engineering Unusual Surface Texture, Dimensions and Morphology Variations of Chiral and Single Crystals. Angew. Chem. Int. Ed. 2021, 6o, 18256-18264.

(48) di Gregorio, M. C.; Shimon, L. J. W.; Brumfeld, V.; Houben, L.; Lahav, M.; van der Boom, M. E. Emergence of Chirality and Structural Complexity in Single Crystals at the Molecular and Morphological Levels. Nat. Commun. 2020, 11, 380.

(49) Vasylyev, M.; Popovitz-Biro, R.; Shimon, L. J. W.; Neumann, R. Inorganic-Organic Hybrid Materials Based on Keggin Type Polyoxometalates and Organic Polyammonium Cations. J. Mol. Struct. 2003, 656, 27-35.

(50) Cho, K.; Yoo, J.; Noh, H. W.; Lee, S. M.; Kim, H. J.; Ko, Y. J.; Jang, H. Y.; Son, S. U. Hollow Structural Effect of Microporous Organocatalytic Polymers with Pyrrolidines: Dramatic Enhancement of Catalytic Performance. J. Mater. Chem. A. 2017, 5, 8922-8926.

(51) Xuan, W.; Ye, C.; Zhang, M.; Chen, Z.; Cui, Y. A Chiral Porous Metallosalan-Organic Framework Containing TitaniumOxo Clusters for Enantioselective Catalytic Sulfoxidation. Chem. Sci. 2013, 4, 3154-3159.

(52) Chygorin, E. N.; Petrusenko, S. R.; Kokozay, V. N.; Omelchenko, I. V; Shishkin, O. V. Tris(2,2'-Bipyridine-

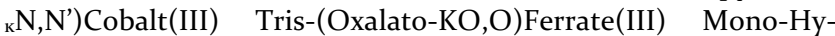
drate. Acta Crystallogr. Sect. E Struct. Reports Online. 2012, 68, 150-156.

(53) Collie, G. W.; Pulka-Ziach, K.; Lombardo, C. M.; Fremaux, J.; Rosu, F.; Decossas, M.; Mauran, L.; Lambert, O.; Gabelica, V.; Mackereth, C. D.; Guichard, G. Shaping Quaternary Assemblies of Water-Soluble Non-Peptide Helical Foldamers by Sequence Manipulation. Nat. Chem. 2015, 7, 871-878.

(54) Wei, S.; Li, X.; Yang, Z.; Lan, J.; Gao, G.; Xue, Y.; You, J. Ligand-Switching and Counteranion-Induced Hierarchical SelfAssembly of Silver-NHC Complexes. Chem. Sci. 2o12, 3, 359-363.

(55) Oji, K.; Igashira-Kamiyama, A.; Yoshinari, N.; Konno, T. Formation, Expansion, and Interconversion of Metallarings in a 
Sulfur-Bridged Au(I)Co(III) Coordination System. Angew. Chem. Int. Ed. 2014, 53, 1992-1996.

(56) Abu-Nawwas, A.-A. H.; Cano, J.; Christian, P.; Mallah, T.; Rajaraman, G.; Teat, S. J.; Winpenny, R. E. P.; Yukawa, Y. An Fe(III) Wheel with a Zwitterionic Ligand: The Structure and Magnetic Properties of $\left[\mathrm{Fe}(\mathrm{OMe})_{2}(\text { Proline })\right]_{12}\left[\mathrm{ClO}_{4}\right]_{\mathrm{a}}$. Chem. Commun. 2004, 2, 314.

(57) Du, M.; Wang, X.; Chen, M.; Li, C. P.; Tian, J. Y.; Wang, Z. W.; Liu, C. Sen. Ligand Symmetry Modulation for Designing a Mesoporous Metal-Organic Framework: Dual Reactivity to Transition and Lanthanide Metals for Enhanced Functionalization. Chem. A Eur. J. 2015, 21, 9713-9719.

(58) Araya, M. A.; Albert Cotton, F.; Matonic, J. H.; Murillo, C. A. An Efficient Reduction Process Leading to Titanium(II) and Niobium(II): Preparation and Structural Characterization of Trans- $\mathrm{MCl}_{2}(\mathrm{Py})_{4}$ Compounds, $\mathrm{M}=\mathrm{Ti}, \mathrm{Nb}$, and $\mathrm{Mn}$. Inorg. Chem. 1995, 34, 5424-5428.

(59) See, R. F.; Kruse, R. A.; Strub, W. M. Metal-Ligand Bond Distances in First-Row Transition Metal Coordination Compounds: Coordination Number, Oxidation State, and Specific Ligand Effects. Inorg. Chem. 1998, 37, 5369-5375.

(6o) Solomon, L. R.; Bond, A. M.; Bixler, J. W.; Hallenbeck, D. R.; Logsdon, K. M. Stability of Monofluoride Complexes of the Irving-Williams Series Acceptors in Methanol. 1983, Inorganic. (22), 1644-1648.

(61) Irving, H.; Williams, R. J. P. The Stability of TransitionMetal Complexes. J. Chem. Soc. 1953, 3192-3210.
(62) Long, G. J.; Clarke, P. J. Crystal and Molecular Structures of Trans-Tetrakis (Pyridine)Dichloroiron (II), -Nickel (II), and Cobalt (II) and Trans-Tetrakis (Pyridine)Dichloroiron (II) Monohydrate. Inorg. Chem. 1978, 17, 1394-1401.

(63) Flack, H. D.; Bernardinelli, G. The Use of X-Ray Crystallography to Determine Absolute Configuration. Chirality 20o8, 690, 681-69o.

(64) Yamashita, T.; Hayes, P. Analysis of XPS Spectra of $\mathrm{Fe}^{2+}$ and $\mathrm{Fe}^{3+}$ Ions in Oxide Materials. Appl. Surf. Sci. 2008, 254, 24412449.

(65) Furlani, A.; Russo, M. V.; Polzonetti, G.; Martin, K.; Wang, H. H.; Ferraro, J. R. Spectroscopic Studies of $\mathrm{FeCl}_{3}$-Doped Polymers of Polyphenylacetylene. Appl. Spectrosc. 1990, 44, 331334.

(66) Garai, B.; Bon, V.; Krause, S.; Schwotzer, F.; Gerlach, M.; Senkovska, I.; Kaskel, S. Tunable Flexibility and Porosity of the Metal - Organic Framework DUT-49 through Postsynthetic Metal Exchange. Chem. Mater. 2020, 32, 889-896.

(67) di Gregorio, M. C.; Ranjan, P.; Houben, L.; Shimon, L. J. W.; Rechav, K.; Lahav, M.; Van Der Boom, M. E. Metal-Coordination-Induced Fusion Creates Hollow Crystalline Molecular Superstructures. J. Am. Chem. Soc. 2018, 140, 9132-9139. 


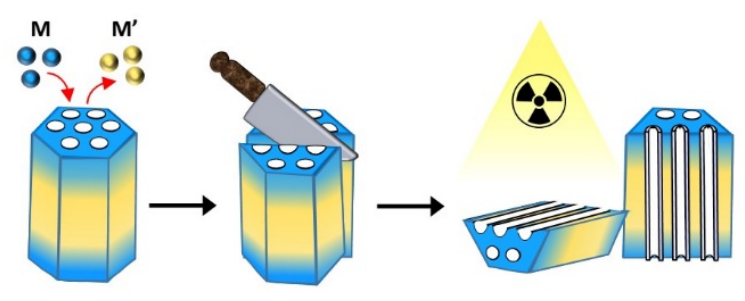

